\title{
Cochlear Otosclerosis: An Undiagnosed Cause of Progressive Sensorineural Hearing Loss
}

https://doi.org/10.47210/bjohns.2020.v28i2.329

Asish Kumar Lahiri, ${ }^{1}$ Anandita Gupta, ${ }^{2}$ Rakesh Vohra, ${ }^{3}$ Shalabh Sharma, ${ }^{1}$ Satinder Singh ${ }^{1}$

\begin{abstract}
Introduction
Otosclerosis presents as conductive or mixed hearing loss depending upon the stage of the disease. Isolated sensorineural hearing loss though known to occur has been rarely reported. Pure cochlear otosclerosis presenting as sensorineural hearing loss should be considered as a differential diagnosis in young patients presenting with progressive hearing loss. The aim of this article is to note the prevalence of cochlear otosclerosis in young patients presenting with progressive sensorineural hearing loss.

Materials and Methods

Retrospective chart analysis of 19 patients who presented with progressive SNHL with unknown etiology was done.

$\underline{\text { Results }}$

Otosclerosis involving the pericochlear region was diagnosed in 27 ears which was identified by high resolution CT scan of temporal bone. In four ears, in addition, there was demineralization just anterior to oval window without clinical evidence of stapes fixation.

Conclusion

In young patients with progressive SNHL, high resolution CT scan of temporal bone should be done to identify progressive cochlear otosclerosis. Medical management should be initiated in these patients to halt the progression of disease.

$\underline{\text { Kevwords }}$

Otosclerosis; Hearing Loss, Sensorineural; Tomography, X-Ray Computed
\end{abstract}

ABSTRACT

$\mathrm{O}$ tosclerosis (OS) is a progressive hereditary disease of collagen which involves foci of bone resorption along with new bone formation in the enchondral bone of the otic capsule. During the active stage a reddish blush may be visible on the promontory and seen through an intact tympanic membrane known as the Schwartze sign. ${ }^{1}$

Fixation of the stapes due to OS focus results in conductive hearing loss (CHL). Expansion of the focus causes involvement of the cochlear endosteum and it manifests as sensorineural hearing loss (SNHL). At this stage the patient may present with mixed hearing loss. ${ }^{1}$ Guild was the first to differentiate between clinical OS and histologic OS. ${ }^{2}$ In clinical OS (fenestral) the disease process begins just anterior to the oval window in an area known as fissula ante fenestrum, resulting in fixation of the stapes and clinically presents as CHL.
It has a prevalence rate of $0.3 \% .^{3}$ In histologic OS one or more foci are located in the bony labyrinth without involvement of cochlear endosteal layer or stapes fixation. ${ }^{4}$ It is an asymptomatic condition and is only detected in serial sectioning of the temporal bones during autopsies. About $12-15 \%$ bones with histologic OS have demonstrated stapedial fixation. ${ }^{3}$ Cochlear OS has also been described in literature when the histologic focus involves the cochlear endosteum and results in atrophy of sensory, neural and supporting tissues of the cochlea

1 - Sir Ganga Ram Hospital, New Delhi

2 - Indian Armed Forces Medical Services

3- Sant Parmanand Hospital, New Delhi

Corresponding author:

Dr Shalabh Sharma

email: drshalabh68@yahoo.co.in 
without fixation of the stapes. ${ }^{5}$

According to Shambaugh, otosclerotic focus involving the cochlear endosteum can result in SNHL and this can occur without fixation of stapes. ${ }^{6}$ Balle and Linthicum also believed that many of the cases where presbycusis is assumed to be the cause of SNHL are in fact due to cochlear OS without stapes fixation. ${ }^{7}$ However, according to Guild, atrophy of neural structures of the cochlea occurs with same frequency in ears with cochlear otosclerosis as in ears without it. ${ }^{2}$ Thus it is debatable whether cochlear otosclerosis presenting as pure SNHL exists as a clinical entity.

Various other conditions can present as progressive SNHL. These include post meningitis cochlear ossification, post-concussion, CNS syphilis, Meniere's disease, noise exposure and endocrinopathy. ${ }^{8}$ Early identification of any possible cause of progressive SNHL helps in initiation of treatment. High resolution computed tomography (HRCT) scan can be used to make a definitive diagnosis of cochlear OS when it is suspected to be the cause of progressive SNHL. The OS lesion can be identified based on the variation in density from the normal otic capsule or altered contour, double ring effect due to demineralization or new bone formation in the bony labyrinth. ${ }^{9}$

The aim of this article is to emphasize that cochlear OS should be considered as a possible cause of progressive SNHL, especially in young subjects. The patient should be evaluated by HRCT of the temporal bone. Early detection would help institute appropriate medical therapy which may halt the progression of disease.

\section{Materials and Methods}

Retrospective chart analysis of patients presenting with history of progressive hearing loss in the otolaryngology outpatient department of our tertiary care hospital from 2012-16 was done. Patients with obvious cause of hearing loss such as Meniere's disease, chronic ear disease, history of exposure to loud sounds or to ototoxic medication and presbycusis were excluded from the study. Data pertaining to otoscopy, tuning fork tests, pure tone audiometry (PTA) and impedance audiometry was extracted from the medical records. The pure tone threshold average at $500 \mathrm{~Hz}, 1 \mathrm{KHz}, 2 \mathrm{KHz}$, $4 \mathrm{KHz}$ for bone conduction (BC) and air conduction (AC) was calculated. Routine blood investigations such as complete blood counts, erythrocyte sedimentation rate (ESR), C reactive protein (CRP), VDRL, fasting and post prandial blood sugar levels were also analysed to rule out any systemic disease associated with SNHL.

HRCT scan of temporal bones was evaluated to identify any likely cause of progressive SNHL. The multidetector CT scanner with following technical parameters is routinely used to identify cochlear otosclerosis in our institution : Kv- $140, \mathrm{~mA}-120$, slice thickness $-0.625 \mathrm{~mm}$, pixels $-0.562: 1$, rotation time $1 \mathrm{sec}$, DFOV $25 \mathrm{~cm}$, algorithm - bone + , retro reconstruction $0.31 \mathrm{~mm}$, window width 3000 and window level 500. Coronal reformation is performed following the acquisition of submillimetric $(0.625 \mathrm{~mm})$ slices in the axial plane. Images are evaluated by optimizing the window width and window level to specifically evaluate areas of demineralization in the middle and inner ear with special attention to cochlear turns, area anterior to footplate of stapes, round window (RW) and internal auditory canal (IAC). In addition, all cases are evaluated for round window obliteration, anatomy of facial nerve canal, jugular bulb foramen, cochlear duct and ossicular fixation. The HRCT scans are reported by single experienced neuroradiologist.

\section{Results}

Nineteen (19) patients with history of progressive hearing loss were identified over a period of four years. Twelve patients were male $(63.2 \%)$ and seven patients were female $(36.8 \%)$. The mean age of patients was $37 \pm 12$ years at the time of presentation. The mean age of onset of hearing loss was $31.6 \pm 11.9$ years. The $\mathrm{AB}$ gap was $<10 \mathrm{~dB}$ in all but three ears (patient no 5,11 , 12). Details of all 19 patients is as per Table I. Of the 38 ears evaluated with HRCT scan, a circumferential rim of hypolucency in the cochlear turns was identified in 27 ears $(71.1 \%)$. In the remaining ears no other pathology was identified. The final diagnosis of cochlear OS in these 27 ears was made on the basis of history, audiometry findings and HRCT. The mean age of patients diagnosed to have cochlear OS was $37.1 \pm 11.2$ years. 
Table I: Demographic profile, radiologic findings and hearing status of all 19 patients

\begin{tabular}{|c|c|c|c|c|c|c|c|c|}
\hline $\begin{array}{l}0 \\
Z \\
E \\
Z \\
E \\
E \\
E\end{array}$ & 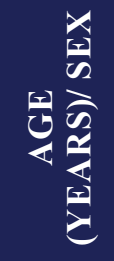 & 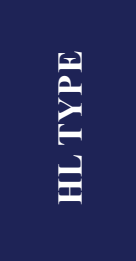 & 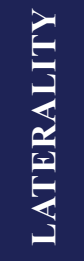 & 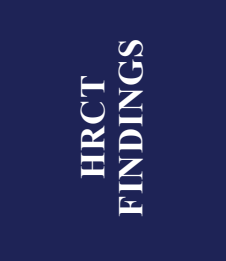 & 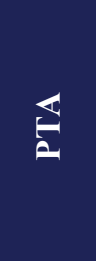 & 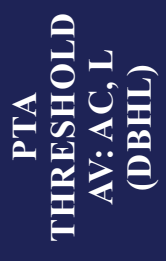 & 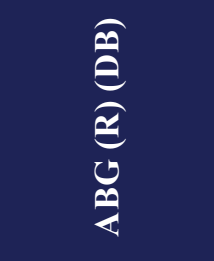 & 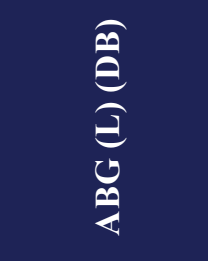 \\
\hline 1 & $38 / \mathbf{M}$ & SNHL & $\mathbf{B} / \mathbf{L}$ & $\begin{array}{l}\text { B/L PC } \\
\text { lucency }\end{array}$ & 68.75 & 38.75 & 7.5 & 3.75 \\
\hline 2 & $35 / F$ & SNHL & $\mathbf{B} / \mathbf{L}$ & $\begin{array}{l}\text { (L) PC } \\
\text { lucency }\end{array}$ & 32.5 & 57.5 & 6.25 & 15 \\
\hline 3 & 27/ M & SNHL & $\mathbf{B} / \mathbf{L}$ & Normal & 61.25 & 66.25 & 7.5 & 10 \\
\hline 4 & $35 / F$ & SNHL & $\mathbf{B} / \mathbf{L}$ & $\begin{array}{l}\text { B/L PC } \\
\text { lucency }\end{array}$ & 71.25 & 60 & 5 & 10 \\
\hline 5 & $20 / \mathrm{M}$ & SNHL & $\mathbf{B} / \mathbf{L}$ & $\begin{array}{l}\text { B/L PC } \\
\text { lucency }\end{array}$ & 61.25 & 56.25 & 13.75 & 8.75 \\
\hline 6 & $53 / \mathrm{F}$ & SNHL & $\mathbf{R}$ & $\begin{array}{c}\text { B/L PC } \\
\text { lucency more } \\
\text { prominent on } \\
\text { (R) }\end{array}$ & 62.15 & 23.75 & 1 & 5 \\
\hline 7 & 49/ M & SNHL & $\mathbf{B} / \mathbf{L}$ & $\begin{array}{l}\text { B/L PC } \\
\text { lucency }\end{array}$ & 41.25 & 60 & 2.5 & 5 \\
\hline 8 & 33/ M & SNHL & $\mathbf{B} / \mathbf{L}$ & $\begin{array}{c}\text { B/L PC } \\
\text { lucency, B/L }\end{array}$ & 80 & 75 & $\begin{array}{c}\text { BC no } \\
\text { response at } 2 \\
\& 4 \mathrm{KHz}\end{array}$ & $\begin{array}{c}\text { BC no } \\
\text { response at } 2 \\
\& 4 \mathrm{KHz}\end{array}$ \\
\hline 9 & $70 / F$ & SNHL & $\mathbf{B} / \mathbf{L}$ & Normal & 70 & 75 & 7.5 & 7.5 \\
\hline 10 & 17/ M & SNHL & $\mathbf{B} / \mathbf{L}$ & Normal & 40 & 50 & 1.25 & 8.75 \\
\hline 11 & 31/ M & $\begin{array}{c}\text { (R) } \\
\text { mixed } \\
\text { HL, (L) } \\
\text { SNHL }\end{array}$ & $\mathbf{B} / \mathbf{L}$ & $\begin{array}{c}\text { B/L PC } \\
\text { lucency. B/L }\end{array}$ & 51.25 & 47.5 & 12.5 & 10 \\
\hline 12 & $55 / F$ & SNHL & $\mathbf{B} / \mathbf{L}$ & $\begin{array}{l}\text { B/L PC } \\
\text { lucency }\end{array}$ & 55 & 58.75 & 8.75 & 12.5 \\
\hline 13 & 31/ M & SNHL & $\mathbf{B} / \mathbf{L}$ & $\begin{array}{l}\text { B/L PC } \\
\text { lucency }\end{array}$ & 78.75 & 81.25 & 7.5 & 10 \\
\hline 14 & $43 / F$ & SNHL & $\mathrm{B} / \mathrm{L}$ & Normal & 48.75 & 51.25 & 7.5 & 7.5 \\
\hline $15 . *$ & $52 / \mathrm{M}$ & SNHL & $\mathbf{B} / \mathbf{L}$ & $\begin{array}{l}\text { B/L PC } \\
\text { lucency }\end{array}$ & 18.75 & 22.5 & 3.75 & 2.5 \\
\hline 16 & $20 / M$ & SNHL & $\mathbf{B} / \mathbf{L}$ & $\begin{array}{l}\text { B/L PC } \\
\text { lucency }\end{array}$ & 48.75 & 51.25 & 2.5 & 8.75 \\
\hline
\end{tabular}


Table I: Demographic profile, radiologic findings and hearing status of all 19 patients (Contd.)

\begin{tabular}{|c|c|c|c|c|c|c|c|c|}
\hline 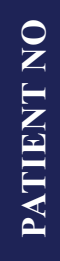 & 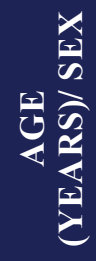 & 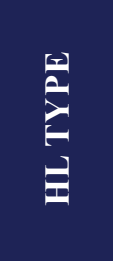 & 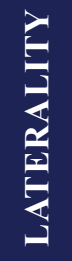 & 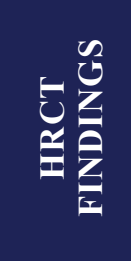 & 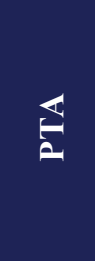 & 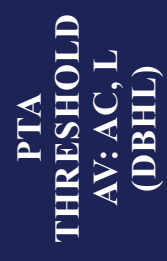 & 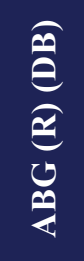 & 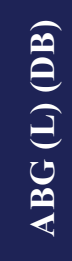 \\
\hline 17 & 32/M & SNHL & B/L & Normal & 30 & 42.5 & 2.5 & 8.75 \\
\hline 18 & $34 / M$ & SNHL & B/L & $\begin{array}{l}\text { B/L PC } \\
\text { lucency }\end{array}$ & 65 & 63.75 & 7.5 & 5 \\
\hline 19 & $34 / F$ & SNHL & B/L & $\begin{array}{l}\text { B/L PC } \\
\text { lucency }\end{array}$ & 73.75 & 52.5 & 6.25 & 6.25 \\
\hline
\end{tabular}

$\mathrm{M}=$ male, $\mathrm{F}=$ female, $\mathrm{HL}=$ hearing Loss, $\mathrm{L}=$ left, $\mathrm{R}=$ right, $\mathrm{B} / \mathrm{L}=$ Bilateral, $\mathrm{SNHL}=$ sensorineural hearing loss, $\mathrm{PC}=$ pericochlear, $\mathrm{FP}=$ footplate, $\mathrm{AC}=$ air conduction, $\mathrm{BC}=$ bone conduction, $\mathrm{ABG}=$ air-bone gap, $\mathrm{dBHL}=$ decibel hearing level.

* Patient no 15 thresholds at 2-8KHz (R) - 20-40dBHL, (L) - 10-75dBHL (B/L high frequency hearing loss).

Fig.1A shows the circumferential rim of hypolucency seen in the cochlear turns of patient no 11 on HRCT. Fenestral otosclerosis in addition to a pericochlear focus was also identified in this patient (Fig 1B). This patient had a mixed type of hearing loss (AB Gap $25 \mathrm{~dB}$ ) at lower frequencies and pure SNHL at other frequencies on $(\mathrm{R})$ side.

Similar HRCT findings were seen in patient no 8 , though he had no evidence of CHL. HRCT scan of patient no 6 showed a faint rim of demineralization in cochlear turns on (L) side as well, even though patient had presented with (R) sided SNHL (Fig. 2A,B).

On the contrary in patient no 2 , no OS focus was seen radiologically in $(\mathrm{R})$ ear even though SNHL was bilateral (Fig. 3). This patient, however, had a higher degree of hearing loss in the (L) ear (PTA average 57.5 $\mathrm{dBHL}$ ) compared to (R) ear (PTA average $32.5 \mathrm{dBHL}$ ). In none of the ears obliteration of the round window (RW), focus in the IAC ossicular fixation, or enlarged vestibular aqueduct was identified. Fig. 4 shows the normal cochlea of patient no 14. Details of patients who were diagnosed with cochlear OS is mentioned in Table

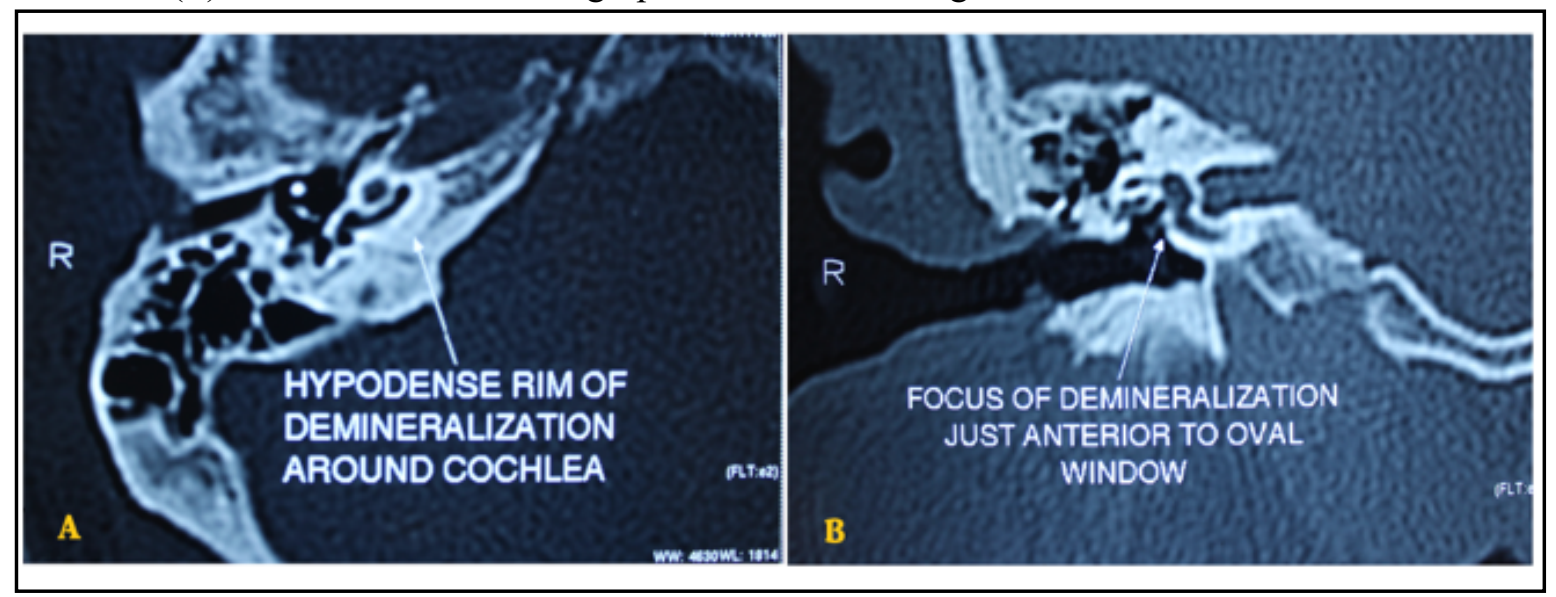

Fig. 1. Axial HRCT image of patient no 11 showing circumferential rim of hypolucency in pericochlear region on (R) side (A). Coronal HRCT image of patient no 11 showing focus of demineralization just anterior to stapes footplate (B). 


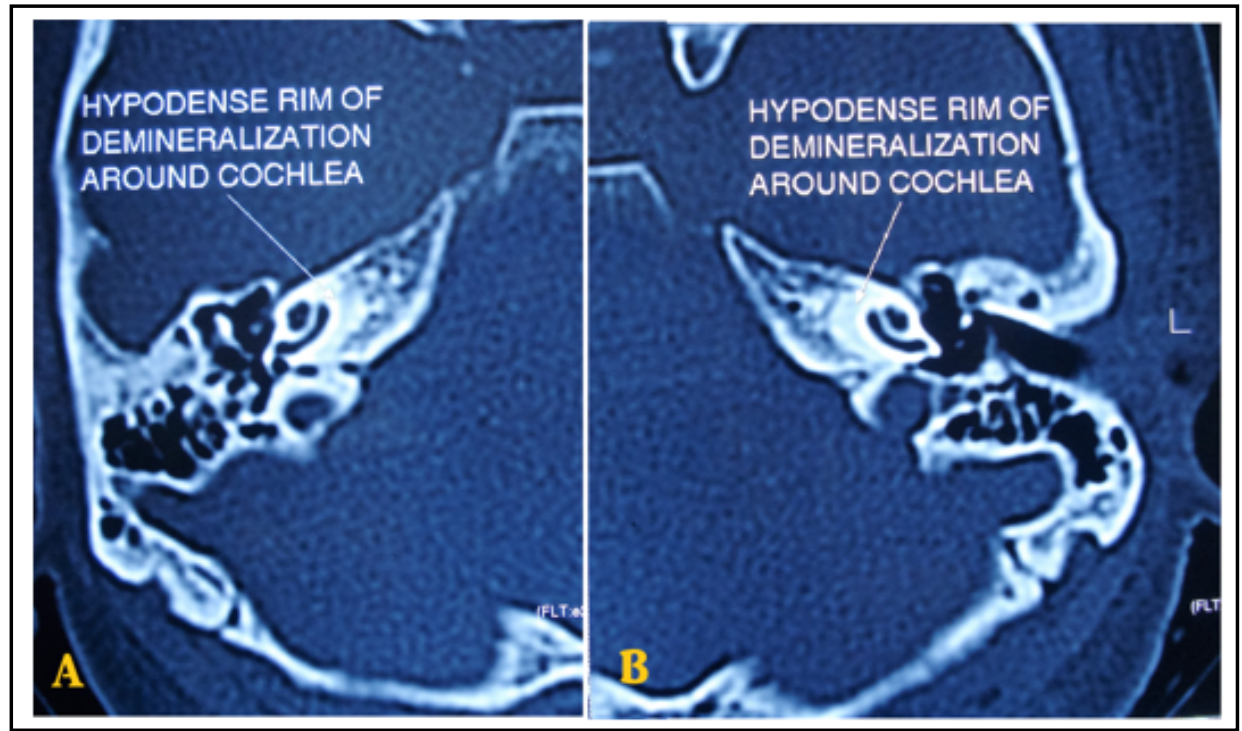

Fig. 2. Axial HRCT image of patient no 6 showing focus of demineralization in pericochlear region on (R) side (A). Axial HRCT image of patient no 6 showing focus of demineralization in pericochlear region on (L) side (B).

II. Most of the patients diagnosed to have cochlear OS had moderate or severe degree of hearing loss (Table III).

Overall, associated symptom in the form of tinnitus was present in $78.9 \%$ ears. Vertigo was present in only three patients (patient no. 14, 15, 19). Blood investigations were negative in all but one (patient no. 10). This patient had elevated inflammatory markers such as ESR and CRP indicative of a possible immune

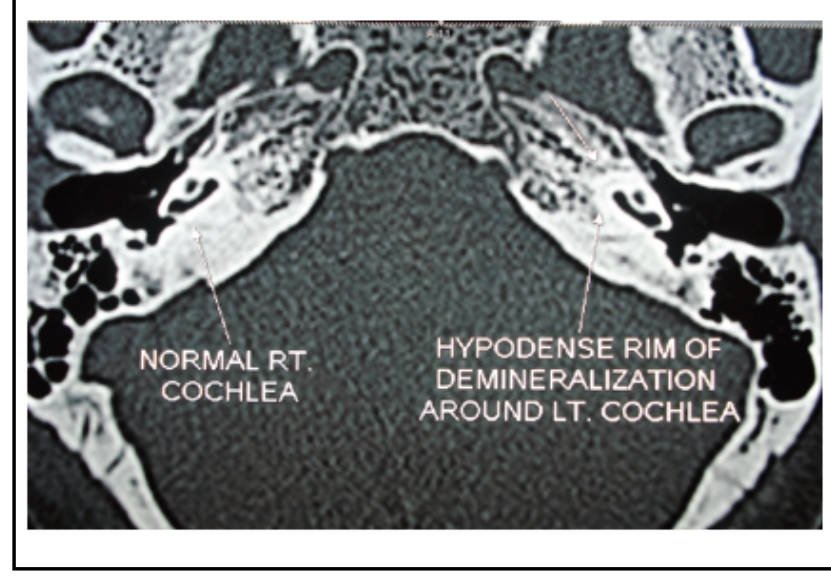

Fig. 3. Axial HRCT image of patient no 2 showing circumferential rim of hypolucency in pericochlear region on (L) side only mediated cause of SNHL. This patient had been advised to attend rheumatology outpatient department to rule out any coexisting systemic autoimmune disease.

Patients who were diagnosed with cochlear OS were started on oral sodium fluoride $(\mathrm{NaF})$ in the dose of 20 $\mathrm{mg}$ twice daily along with oral calcium and vitamin D3. The dose was increased (20 mg thrice daily) in patient no 15 as he subjectively reported some deterioration of hearing, even though other associated symptoms had

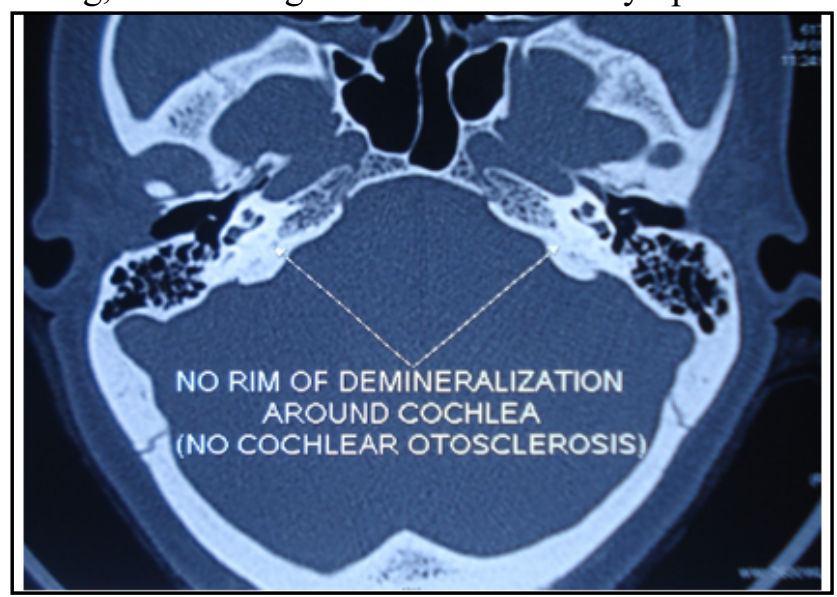

Fig. 4. Axial HRCT image of patient no 14 showing normal cochlea. 
Table II: Characteristics of cases of sensorineural hearing loss found to have cochlear otosclerosis.

\begin{tabular}{|c|c|c|}
\hline & & \\
\hline 1 & $\begin{array}{c}\text { Age at onset } \\
\text { (years } \pm \text { SD) }\end{array}$ & $32.5 \pm 11.4$ \\
\hline 2 & $\begin{array}{c}\text { Positive family } \\
\text { history }\end{array}$ & $\begin{array}{c}2 \text { of } 14 \text { subjects } \\
(14.3 \%)\end{array}$ \\
\hline 3 & $\begin{array}{c}\text { History of } \\
\text { tinnitus }\end{array}$ & 23 of 28 ears $(82.1 \%)$ \\
\hline 4 & $\begin{array}{c}\text { History of } \\
\text { vertigo }\end{array}$ & 2 of 14 subjects \\
$(14.3 \%)$
\end{tabular}

$S D=$ standard deviation

disappeared. Skeletal X Rays were done which excluded any pre-existing skeletal flourosis in these patients. Duration of therapy, change in subjective symptoms of patients who were started on therapy is as per Table IV.

Record of hearing thresholds after at least six months of $\mathrm{NaF}$ therapy was available only for six patients (Fig. 5). The median follow up period was 11 months (range 6 to 16). PTA average thresholds improved in five ears (mean, $10.5 \pm 7.27 \mathrm{~dB}$ ) and seven ears showed slight progression (mean, $4.46 \pm 4.07 \mathrm{~dB}$ ). When comparing mean $\mathrm{BC}$ thresholds of these 12 ears pre and post therapy at individual frequencies, mean improvement at 0.5 $\mathrm{KHz}, 1 \mathrm{KHz}$ and $4 \mathrm{KHz}$ was $-1.25 \mathrm{~dB}(95 \% \mathrm{CI},-1.29$ to $-1.21),-1.25 \mathrm{~dB}(95 \% \mathrm{CI},-1.40$ to 1.10$),-1.67 \mathrm{~dB}(95 \%$ CI, -1.88 to -1.45$)$ respectively. There was deterioration at $2 \mathrm{KHz}$ (mean, $2.5 \mathrm{~dB} ; 95 \% \mathrm{CI}, 2.30$ to 2.70 ).

\section{Discussion}

OS is unique to the human temporal bone. In 1735 , Valsalva first described bony ankylosis of the stapes to oval window (OW) margins in temporal bone dissection of a man who had been deaf during his lifetime. In 1852,
Table III: Degree of hearing in ears diagnosed with cochlear otosclerosis

\begin{tabular}{|c|c|c|}
\hline$\frac{\theta}{\not Z}$ & 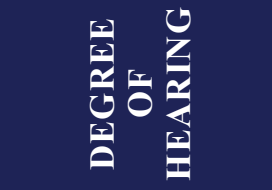 & 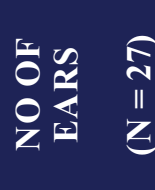 \\
\hline 1 & Normal (0-25) & 03* \\
\hline 2 & Mild (26-40) & 1 \\
\hline 3 & Moderate (41-60) & 12 \\
\hline 4 & Severe $(61-80)$ & 10 \\
\hline 5 & Profound $(>80)$ & 1 \\
\hline
\end{tabular}

*Patient no 06 - (L) ear thresholds were normal even though there was radiologic evidence of cochlear OS. Patient no 15 - pure tone average was normal, elevated thresholds at $2-8 \mathrm{KHz}$.

** WHO Grades of hearing impairment

Toynbee found fixation of stapes in 39 bones out of 1659 temporal bone dissections and subsequently considered it to be the commonest cause of deafness. The term otosclerosis, however, was first used by von Troltsch in 1861. The first account of histology of this disease was given by Politzer. It was his work that established OS as a primary disorder of otic capsule and not secondary to middle ear catarrh as was believed at that time. ${ }^{10}$

Various theories describe the causation and pathogenesis of this entity which include metabolic disorders, vascular disease, infection, trauma, developmental disorder, immune mediated causes and viral infection. Exacerbation of symptoms during period of increased hormonal activity such as pregnancy has been documented suggesting a possible hormonal mechanism. It is predominantly a disease of the Caucasian race. ${ }^{2,3}$ It is extremely rare in oriental and black races. ${ }^{1}$ It is inherited as an autosomal dominant trait with incomplete penetrance. The reported incidence of sporadic cases is about $30 \%{ }^{1}$

The most common site of occurrence of OS is anterior aspect of OW. This results in fixation of the stapes which may be fibrous initially and later becomes bony ankylosis. Other areas of predilection are RW, apical medial wall of cochlea, anterior and posterior wall of 
Table IV: Summary of subjective change in symptoms of patients started on sodium flouride therapy.

\begin{tabular}{|c|c|c|c|}
\hline $\begin{array}{l}\text { PATIENT } \\
\text { NO }\end{array}$ & INITIAL SYMPTOMS & $\begin{array}{l}\text { DURATION } \\
\text { OF THERAPY } \\
\text { (MONTHS) }\end{array}$ & $\begin{array}{c}\text { CHANGE IN } \\
\text { SYMPTOMS POST TREATMENT }\end{array}$ \\
\hline 1 & HL, tinnitus & 6 & $\begin{array}{l}\text { HL stabilized, no tinnitus, discontinued treatment } \\
\text { after six months due to gastric irritation }\end{array}$ \\
\hline 2 & HL, tinnitus & $<06$ & Gastric irritation, Lost to follow up \\
\hline 4 & HL & 16 & (R)Slight deterioration, (L) improved thresholds \\
\hline 5 & HL, tinnitus & 15 & HL stabilized, no tinnitus \\
\hline 6 & HL, tinnitus & 6 & Slight progression of $\mathrm{HL}$, tinnitus persistent \\
\hline 7 & HL, tinnitus & $<06$ & Lost to follow up \\
\hline 8 & HL, tinnitus & $<06$ & Lost to follow up \\
\hline 11 & HL, tinnitus & 7 & Lost to follow up \\
\hline 12 & HL, tinnitus & $<06$ & Lost to follow up \\
\hline 13 & HL, tinnitus & 6 & HL stabilized, no tinnitus \\
\hline 15 & $\begin{array}{l}\text { HL, tinnitus, discomfort } \\
\text { to loud sounds, vertigo }\end{array}$ & 10 & $\begin{array}{l}\text { Discomfort to loud sounds and vertigo relieved, } \\
\text { slight progression of HL }\end{array}$ \\
\hline 16 & HL, tinnitus & 12 & Improved thresholds, no tinnitus \\
\hline 17 & HL & 4 & Progression of HL, lost to further follow up \\
\hline 18 & HL, tinnitus, vertigo & 2 & $\begin{array}{l}\text { Tinnitus stopped, persistence of dizziness after } \\
\text { two months, lost to further follow up }\end{array}$ \\
\hline
\end{tabular}

$H L=$ Hearing loss

IAC and within the stapedial footplate. ${ }^{1}$ Conductive deafness does not occur till the lesion involves the oval window area. ${ }^{1}$ Overall, the incidence of conductive deafness due to OS in adult white population is 3 to 10 per $1000 .^{2}$ OS is more common in females. Positive family history is found in two third of cases. ${ }^{1}$ In our study though, $35.7 \%$ of the patients diagnosed to have cochlear OS were females and positive family history of deafness was present only in two subjects.

The exact incidence of various types of OS is not known. Guild has reported a higher proportion of histologic OS (85\%) compared to clinical OS (15\%) in his series. ${ }^{2}$ In another series by Schuknecht and Barber, clinical OS was found in $75 \%$, histologic OS in $25 \%$ and cochlear OS only in $3 \%$ of the bones studied. ${ }^{11}$ The most likely difference as noted by Schuknecht and Barber is that Guild's series included bones from unselected routine autopsy cases whereas their series included bones of otologic interest.

According to Shambaugh, occurrence of progressive SNHL in a patient with family history of OS, presence of Schwartze sign in an ear with pure SNHL, insidious onset of SNHL in early life or pure SNHL documented in one of the ears of a patient already known to have stapes fixation in the contralateral ear, are some of the features suggestive of cochlear OS.6 In our series, the mean age of onset in patients who were diagnosed to have cochlear OS was 32.5 \pm 11.4 years and mean age of presentation was $37.1 \pm 11.2$ years. Only two patients had a first degree relative with early onset of hearing loss (patient no. $1 \& 15$ ). Schwartze sign was seen bilaterally only in one patient (patient no. 5). Beales has postulated that OS should be considered as having two components - a cochlear component and a mechanical one which 


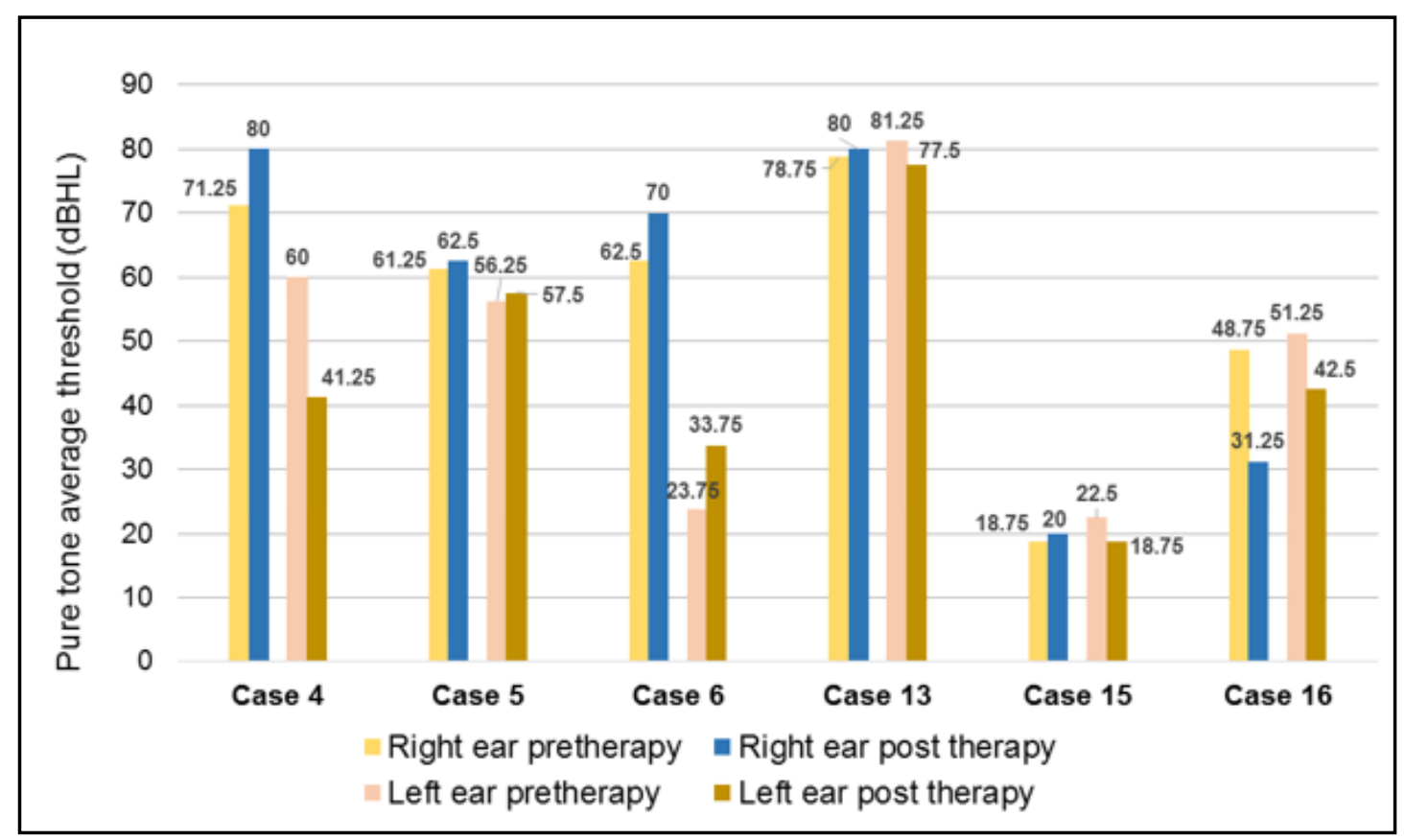

Fig. 5. PTA average threshold pre and post therapy (for patients who continued sodium flouride for $>6$ months).

involves fixation of stapes. The two components may occur independently or progress in combination producing a variety of clinical presentation ranging from pure cochlear type to obliterative type. ${ }^{10}$

SNHL occurring in cochlear OS has been attributed to release of enzymes such as trypsin, alpha-1 antitrypsin, ribonuclease which are toxic to the Organ of Corti. Causse and Chevance were able to demonstrate lysosome containing histiocytes in the advancing edge of otosclerotic lesion. ${ }^{12}$ According to Parahy and Linthicum, SNHL can also occur in OS without the involvement of cochlear endosteum. In such cases it is believed that certain proteolytic enzymes that are harmful to the cochlea reach the cochlear endosteum through small bony channels present in the focus resulting in atrophy of stria vascularis and hyalinization of spiral ligament. ${ }^{13}$ Lowering of the perilymph $\mathrm{pH}$ due to release of hydrogen ions from the spongiotic focus is also known to have deleterious effect on the cochlear structures. ${ }^{14}$

The existence of cochlear OS as a definite entity has been controversial. Schuknecht and Kirschner have strongly refuted the concept of cochlear OS presenting as pure SNHL. They postulated that when the otosclerotic lesion is severe enough to involve cochlear endosteum resulting in atrophy of sensory, neural and supporting structures, it involves the stapes as well. ${ }^{4,5}$ They have also stated that severe OS can cause SNHL, yet there is no conclusive evidence that OS of lesser magnitude can cause pure SNHL. ${ }^{5}$

Balle and Linthicum on the other hand have postulated that cochlear OS can be a cause of pure SNHL. They have reported on histologic features of cochlear OS in seven temporal bones documented to have moderate to profound degree of hearing loss. The histologic findings included atrophy of the stria vascularis, hyalinization of the spiral ligament, hair cell and ganglion cell loss, hydrops and distortion of cochlear walls. They were also able to correlate the severity of histologic findings to the degree of hearing loss. According to them histologic studies of temporal bones cannot reflect the true incidence of pure cochlear OS. ${ }^{7}$

A definitive diagnosis of pure cochlear OS in a live patient is not possible. ${ }^{6}$ Earlier Valvassori reported use of polytomography as a reliable tool for identifying lesions of cochlear otosclerosis. ${ }^{15}$ In the past, Freeman 
also had emphasized the importance of polytomography as he could identify 53 cases of cochlear OS in his series of 100 consecutive cases of progressive SNHL. ${ }^{8}$ In the present era, HRCT scan of temporal bone is considered to be of immense value in diagnosing cochlear OS. ${ }^{16,17}$ Radiologically, it appears as a hypodense lesion or an area of irregularity or increased thickness in the otic capsule. ${ }^{18}$ The area of lucency can be single, multiple or confluent. ${ }^{19}$ The CT grading system for OS proposed by Rotteveel is well accepted classification system. The classification is based on location and type of lesion. Fenestral type is classified as Grade 1, retrofenestral type as Grade 2A: double ring or halo effect, Grade 2B: narrowing of basal turn, Grade 2C: both, Grade 3: diffuse confluent lesions.20, 21 In our study all lesions were Grade 2A with the exception of two patients who also had a coexisting Grade 1 lesion. Lagleyre et al have reported that HRCT has a sensitivity of $95.1 \%$ and specificity of $99.5 \%$ in diagnosing OS. Using their protocol, they were able to pick up otosclerotic hypodensities anterior to the $\mathrm{OW}$, in pericochlear region, RW and in the IAC. A definitive diagnosis of OS was established at the time of surgery in this study. In their series of 200 patients, 51 patients also had a pure SNHL in the contralateral ear. HRCT was positive in $68 \%$, negative in $22 \%$ and doubtful in $10 \%$ of the 51 ears with pure SNHL.22 Foci less than 2-3 mm or inactive lesions where the density of lesion has become similar to that of surrounding bone are likely to remain undetected in HRCT. ${ }^{17,18}$

In our series we have used HRCT scan to evaluate the temporal bones of young patients who presented with progressive hearing loss. Otosclerotic focus could be identified in 27 out of 38 ears evaluated. We could also identify cochlear OS in the contralateral ear of a patient which had yet not manifested with hearing loss. We did not correlate the site of OS focus with the audiologic frequencies involved though there are studies in which correlation of abnormal densitometric points with the audiologic frequencies involved has been demonstrated. ${ }^{18}$ We believe that HRCT scan is an essential tool in evaluating patients with unilateral or bilateral progressive SNHL which is inappropriate for age. It helps in establishing a diagnosis as well as early initiation of treatment which can halt further progression of hearing loss.

Medical management of cochlear OS is in the form of $\mathrm{NaF}$ along with oral calcium and vitamin D3. It promotes the calcification of the otospongiotic lesion. Otosclerotic bone due to its high metabolic activity selectively takes up fluoride compared to normal skeletal bone resulting in formation of fluorapatite which is hard and resists bone resorption. ${ }^{23}$ The bone resorption and vascularity of the spongiotic bone is reduced resulting in maturation of the focus. ${ }^{14,23} \mathrm{NaF}$ also inhibits the release of enzymes by the otosclerotic focus which are known to cause SNHL. ${ }^{13,23}$ It is used in the dosage of $40 \mathrm{mg}$ per day for two years. Once the hearing loss stabilizes a maintenance dose of $20 \mathrm{mg}$ per day for one's lifetime can be given. ${ }^{10} \mathrm{NaF}$ has been extensively used by Shambaugh and he found that with its prolonged use the re-calcification of the focus increases which is apparent radiologically, however, after a variable period of time.6 Biphosphonates which are potent anti-bone resorption agents have also been advocated in management of OS in recent literature. ${ }^{24,25}$

Joint pains, fluorosis of lumbar spine, allergic dermatitis, hair loss, dental mottling, gastric irritation are some of the side effects reported after prolonged use of NaF. ${ }^{23,26}$ Gastric discomfort can be reduced by simultaneous intake of calcium carbonate though it can reduce absorption due to formation of calcium fluoride. ${ }^{23,27}$ In our study two patients (Patient no. 1 \& 2) developed gastric irritation which was severe enough to discontinue treatment. Patient no 1 restarted therapy after a gap of one year. Another patient (Patient no. 13) discontinued treatment as he developed elevated serum uric acid levels while on NaF therapy. Skeletal X Ray should be done prior to starting the treatment as well as during the treatment to watch for developing skeletal fluorosis. ${ }^{10}$

There is paucity of clinical evidence supporting the role of sodium fluoride in treating OS. ${ }^{26,28}$ In a randomized controlled trial using $\mathrm{NaF}$ in patients with OS (20 mg twice daily for two years) statistically significantly greater deterioration of hearing was seen in the untreated arm..$^{29}$ Derks et al demonstrated improved $\mathrm{BC}$ thresholds for low and high frequencies in the ears treated with $\mathrm{NaF}$ compared to untreated ears which had a statistically significant progression of SNHL. ${ }^{30}$ Forquer et al also found that hearing loss in patients with clinical 
as well as cochlear OS stabilized or progressed slowly when treated with $\mathrm{NaF}^{31}$ In our study, we found benefit either in the form of improved or stabilized thresholds in a small group of patients whose follow up audiogram was available, or disappearance of associated symptoms such as tinnitus with NaF therapy. (Table IV, Fig. 5)

We have presented data of 19 patients who presented with progressive SNHL. HRCT scan helped in establishing diagnosis of cochlear OS in 14 patients who were started on $\mathrm{NaF}$ therapy. As most of the patients in our series had moderate or severe degree of hearing loss, our intent of starting medical therapy was to prevent the progression of hearing to profound disabling levels. Limitation of this study is lack of objective assessment of the response to therapy in all the patients as some of them were lost to follow-up.

We feel that absence of immediate benefit and need for prolonged therapy limits the compliance. Possible role of $\mathrm{NaF}$ therapy in stopping further progression of hearing loss and associated symptoms must be emphasized during counseling. Also increase in dosage can be considered in those patients who continue to have progressive disease as recommended by Shambaugh. ${ }^{6}$

\section{Conclusion}

There are no conclusive studies which can prove or refute the concept of cochlear OS causing pure SNHL. However, cochlear otosclerosis has been considered as a cause of pure SNHL in literature. It is not possible to histologically prove cochlear otosclerosis in life. In our clinical practice we do come across young patients with SNHL which is progressive. Identifiable causes of SNHL such as cochlear otosclerosis should always be suspected in these patients. In most instances the cause of SNHL is assumed to be secondary to noise, ototoxic medication, head trauma or even presbycusis if the patient's age and history so permits. HRCT of temporal bones in these patients is seldom asked for. Hence, cochlear OS often remains undiagnosed. We recommend that all patients with early onset unilateral or bilateral progressive SNHL should undergo HRCT temporal bone in addition to the routine investigations. Early detection of cochlear OS will help institute medical therapy which may halt the further progression of hearing loss.

Authors'Note: This paper was presented in the Indian Society of Otology Conference in November, 2016 at Calicut, Kerala (India).

\section{References}

1. MN Wali. Otosclerosis. Can Fam Physician. 1987; 33: 1491-3

2. Guild SR. Histologic otosclerosis. Annal Otol Rhinol Laryngol. 1944; 53: 46

3. Declaua F, Spaendonck MV, Timmermans JP, Michaels L, Liang J, Qiu JP, et al. Prevalence of otosclerosis in an unselected series of temporal bones. Otol Neurotol. 2001; 22: 596-602

4. Schuknecht HF. Cochlear otoslerosis- A continuing fantasy. Arch Otolaryngol Head Neck Surg. 1979; 222: 79-84

5. Schuknecht HF, Kirschner JC. Cochlear otosclerosis: fact or fantasy. Laryngoscope 1974; 84: 766-82

6. Shambaugh G, Jr. The therapy of cochlear otosclerosis. Ann Otol Rhinol Laryngol. 1966; 75: 579-83

7. Linthicum FH, Balle V. Histologically proven cochlear otosclerosis with pure SNHL. Annal Otol Rhinol Laryngol. 1984; 93: 105-11

8. Freeman J. Progressive Sensorineural hearing loss and cochlear otosclerosis: A prospective study. Laryngoscope 1979; 89: 1487-521

9. Franceschini SS, Ravecca F, De Vito A, Berrettini S. Progressive sensorineural hearing loss in cochlear otosclerosis. Acta Otorhinolaryngol Ital. 1998; 18: 59-65

10. Beales PH. Otosclerosis - past and present. J. R. Soc. Med. 1979; 72: 553-61

11. Schuknecht HF, Barber W. Histologic variants in otosclerosis. Laryngoscope 1985; 95: 1307-17

12. Causse JR, Chevence LG. Sensorineural hearing loss due to cochlear otospongiosis: etiology. Otolaryngol Clin North Am. 1978; 11: 125-34

13. Parahy C, Linthicum FH Jr. Otosclerosis: relationship of spiral ligament hyalinization to sensorineural hearing loss. Laryngoscope 1983; 93: 717-20

14. Petrovic AG, Stuzmann JJ, Shambaugh GE Jr. Experimental studies on pathology and therapy of otospongiosis. Am J Otol. 1985; 6: 43-50

15. Valvassori GE. Radiologic diagnosis of cochlear otosclerosis. Laryngoscope. 1965; 75: 1563-71

16. Veillon F, Riehm S, Emachescu B, Haba D, Roedlich MN, Greget M, et al. Imaging of the windows of the temporal bone. Semin Ultrasound CT MR. 2001; 22: 271-80

17. Mafee MF, Henrikson GC, Deitch RL, Norouzi P, Kumar A, Kriz R, et al. Use of CT in stapedial otosclerosis. Radiology 1985; 156: 709-14 
18. Guneri EA, Ceryan K, Ada E, Guneri A. High resolution computed tomographic evaluation of cochlear capsule in otosclerosis: relationship between densitometry and sensorineural hearing loss. Ann Otol Rhinol Laryngol. 1996; 105: 659-64

19. Youssef O, Rosen A, Chandrashekhar S, Lee HS. Cochlear otosclerosis: The current understanding. Ann Otolol Rhinol Laryngol. 1998; 107: 1076-9

20. Rotteveel LJ, Proops DW, Ramsden RT, Saeed SR, van Olphen AF, Mylanus EA. Cochlear implantation in 53 patients with otosclerosis: Demographics, Computed tomographic scanning, surgery and complications. Otol Neurotol. 2004; 25: 943-52

21. Merkus P, van Loon MC, Smit CF, Smit C, de Cock Adrianus FC, Hensen EF. Decision making in advanced otosclerosis: An evidence based strategy. Laryngoscope. 2011; 121: 1935-41

22. Lagleyre S, Sorrentino T, Calmels MN. Shin YJ, Escude B, Deguine O, et al. Reliability of High Resolution CT Scan in Diagnosis of Otosclerosis. Otol Neurotol. 2009; 30: 1152-9

23. Causse JR, Causse JB, Uriel J, Berges J, Shambaugh GE Jr, Bretlau P. Sodium fluoride therapy. Am J Otol. 1993; 14: 48290

24. Kennedy DW, Hoffer ME, Holliday M. The effects of etidronate disodium on progressive hearing loss from otosclerosis.
Otolaryngol Head Neck Surg. 1993; 109: 461-7

25. Brookler K. Medical treatment of otosclerosis: rationale for use of bisphosphonates. Int Tinnitus J. 2008; 14: 92-6

26. Hentschel MA, Huizinga $P$, van der Velden DL, Bittermann AJN, van der Heijden GJM, Grolman W. Limited evidence for the effect of sodium fluoride on deterioration of hearing loss in patients with otosclerosis: A systematic review of literature. Otol Neurotol. 2014; 35: 1052-7

27. Deka RC, Kacker SK, Shambaugh GE Jr. Intestinal absorption of fluoride preparations. Laryngoscope 1978; 88:1918-21

28. Cruise AS, Singh A, Quiney RE. Sodium fluoride in otosclerosis treatment: review. J Laryngol Otol. 2010; 124: 583-6

29. Bretlau P, Salomon G, Johnsen NJ. Otospongiosis and sodium fluoride. A clinical double-blind, placebo-controlled study on sodium fluoride treatment in otospongiosis. Am J Otol. 1989; 10: $20-2$

30. Derks W, De Groot JA, Raymakers JA, Veldman JE. Fluoride therapy for cochlear otosclerosis? An audiometric and computerized tomography evaluation. Acta Otolaryngol. 2001; 121: 174-7

31. Forquer BD, Linthicum FH, Bennett C. Sodium fluoride: Effectiveness of treatment for cochlear otosclerosis. Am J Otol. 1986; 7: 121-5. 